\title{
Vertical Distribution of Wind-eroded Dust within 50m High at Minqin Dust Source Area in North-Western China
}

\author{
Duo-qing MAN, Shi-zeng LIU*, De-lu LI, Zi-zhu YAN, Qing-zhong ZHENG, Yin-ke LI and Yuan-yan WANG \\ Minqin National Studies Station for Desert Steppe Ecosystem, State Key Laboratory Nurturing Base of Desertification and \\ Aeolian Sand Disaster Combating, Gansu Desert Control Research Institute, Lanzhou, Gansu Province, P.R.China
}

\begin{abstract}
Aeolian Dust Samplers (ADS) were fixed to a $50 \mathrm{~m}$ high steel tower above the ground at Minqin sand-dust source area in north-western China, dust was collected and treated respectively after each sand-dust storm event and end of the month in a year round. The vertical distribution of dust mass monthly and timely agreed the function of $q_{\mathrm{h}}=a+b \exp (-h / c)$, it showed that the dust particle concentration decays exponentially with the height. The correlation between dust mass and height was reasonably well. $a, b$ and $c$ were Coefficients, mainly driven by wind velocity, $a$ and $b$ positively increased with wind velocity, $b$ was more obvious and sensitive than $a$, implying that the dust particle concentration decays more rapidly as wind velocity decreases. However, $c$ decreased with wind velocity increasing and negative with $a$ and $b$. The maximum and mean dust particle size was reduced with the height increase and varied with wind velocity. The standard deviation $\left(\sigma_{I}\right)$ of dust particle size distribution had an increasing tendency with the height from poorly to very poorly sorted; all skewness $\left(\mathrm{Sk}_{\mathrm{I}}\right)$ was very positively fine skewed; kurtosis $\left(\mathrm{K}_{\mathrm{G}}\right)$ had a reduced tendency with the height from very leptokurtic to leptokurtic. It all revealed that dust particles exists from local to remote areas extensively. Minqin is not only a main dust source area but also a main corridor of sand-dust storms in north-western China.
\end{abstract}

\section{Keywords-sand dust; vertical distribution; source area}

\section{INTRODUCTION}

Arid and semi-arid regions of the world, covering about one-third of the Earth's land surface, are the major source of wind-eroded dust (Youngsin Chun et al., 2001). Within Asia, the arid inland region of north-western China has been recognized a particularly rich contributor of atmospheric dust (Zhang et al., 1997). Scientific awareness of biogeochemical cycle and in particular of the importance Chinese aeolian dust in the atmosphere is growing (Zhang et al., 1997; Du et al., 2002). The close relationship between desert dust and ecosystem degradation also widely recognized (Xia and yang, 1996; yang et al., 2001). Dust contributors in dust source area are believed to be the alluvial and lacustrine sediments, Gobi desert, wadis, deteriorated land and dunes (Wang and Dong et al., 2005). Measuring dust in motion can be done in some ways, the main way is to collect it by arrangement of shallow trays on a pole or a tower but at much great expense, and generally trays were arranged at $2.5 \mathrm{~m}$ or $5 \mathrm{~m}$ high above the ground (Fryrear et al, 1986; Dress et al., 1993), the comparison of collecting methods among traps, glass marbles, moss bags or plastic mats trap has also been done (Goodman et al, 1979; Hall et al, 1994; McTainsh et al, 1999; Breuning-Madsen and Awadzi, 2005), and showed a good linear correlation (Qian and Dong, 2004), some measurements in recent years were carried out at tops of city's buildings in China (Zhou et al, 2002; Wang and Dong et al, 2005). With aspirating devices that suck in dust-laden air, capturing the dust either on a filter, in a gravitational trap, or electrostatically, but trapping the dust can create problems if the filter interferes with flow, engine troubles or even power failure in rural desert area (Offer and Goosens, 1990; Nickling and Gillies, 1993). Another group of methods depends on light-extinction. Including methods of visibility or of the extinction of solar radiation. Calibrated methods against dust collection, these can give quite good results cheaply, and also facing some standards or interfere problems (McTainsh, 1980; Middleton, 1989). More sophisticated equipment can be used, such as, ground-based (or ship-based) sun photometer, radar, sun sky radiometer, web camera and so on (Ben Mohamed and Frangi, 1986; D’Almeida et al., 1983; Pisani et al., 2005; Reid et al., 2003; Iino et al., 2004). Dust cloud densities, transport routes and forecast can be estimated by satellite imageries (Legrand et al., 1989; Holben et al., 1991). Also despite a few studies on sand-driving wind structures at near ground surfaces, wind tunnel simulation, air dust concentration, particle size, chemical elements, mode of transportation of dust storm have been researched by various techniques for decades. However, few are known on vertical distribution of wind-eroded dust within $50 \mathrm{~m}$ high above the ground in arid inland source area (Gillette and hanson,1989; Tegen and Fung, 1994; Zhou et al, 2002; Dong et al, 2002; 2003; 2004; Amal Kar, 2004). Most of lives in the globe live in this vertical range, and are influenced seriously by frequent dust storms in dust source area. So understanding dust vertical distribution in dust source area has a great significance.

The Shiyang River basin where population is about 2 million, one of the main arid inland river basins of northwest China, is situated in the east of Hexi region of Gansu province. Its lower reaches in Minqin region are surrounded by Badain Jarin Desert and Tengger Desert in the east, west and north. Over the last 50 years, natural vegetative ecosystem in Minqin has been seriously degraded because of population increasing, surface run off decreasing and groundwater table declined continually. Old Qingtu Lake of $4000 \mathrm{~km}^{2}$ - the terminal lake of Shiyang River Basin-has dried up and covered by mobile 
and semi-fixed dunes, two deserts connected together and oasis shrunk rapidly in the region. The area of desertified land at the rate of $1.35 \%$ annually (Wang and Cheng, 2000), dust storms have become more frequent since 1990s, now considered one of the main source regions of dust storm in China, Shiyang river basin, especially, the lower reaches has been focused by national and international societies in latest decade. In fact, most dust storms in China originated from three geographic areas -the Taklimakan Desert, the Hexi Corridor and western Inner Mongolia Plateau, and the central Inner Mongolia Plateau (Wang et al., 2004), dust storms from former two of them, which are key dust source areas in China (Zhang et al., 1998), can not avoid to pass through Minqin region, then, move to the east country and Asia/Pacific Ocean regions (Zhang et al., 1997; 1998), Minqin region is not only a main dust source area but also the key dust storm corridor in China. However, what the dust vertical distribution above the ground in main dust source and corridor areas remains an important issue, needs some scientific practices to research and to understand it.

In the current research, a $50 \mathrm{~m}$ high steel tower has been set up in typical natural dust source area of lower reaches of Shiyang River basin, a year round monitoring observation in time and space was taken, the dust production, grain size and wind velocity related to the sand - dust storms within $50 \mathrm{~m}$ high above the ground was documented.

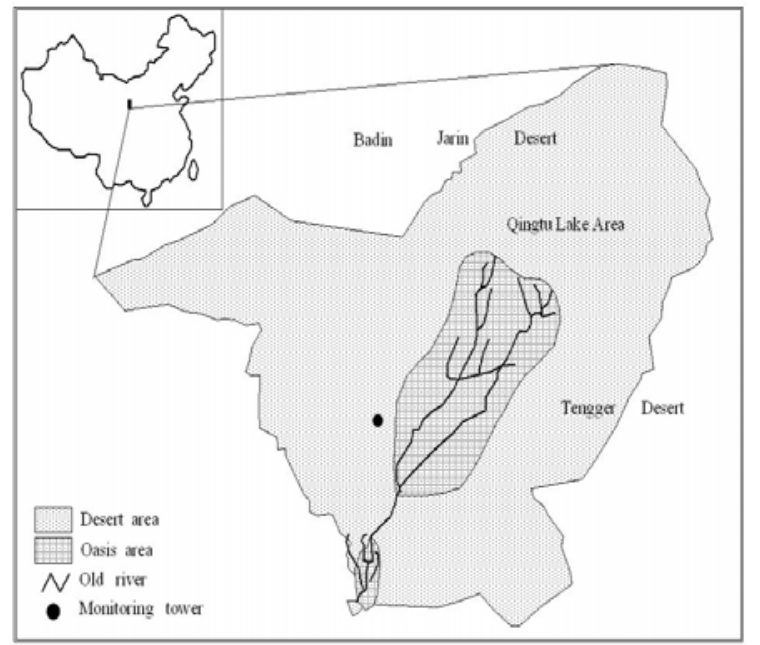

Fig.1. Minqin sketch map of desert scope and monitoring site

\section{MATERIALS AND METHODS}

\section{A. Experimental Site}

The experimental site was selected at $102^{\circ} 55^{\prime} 11^{\prime \prime} \mathrm{E}$ and $38^{\circ} 37^{\prime} 44^{\prime \prime} \mathrm{N}$ at natural area of Minqin region in the lower reaches of Shiyang River basin (Fig. 1), 94.2\% of total land of $16,000 \mathrm{~km}^{2}$ in Minqin is desert, and others are oasis and desertified land. Vast areas of the alluvial and lacustrine sediments, Gobi, wadis, coppice mound, salty land, deteriorated land, deflation residual hill and moving dunes are distributed for dust source. It is one of the most frequent areas for sand-dust storms in China (Middleton et al, 1986).

The climate in Minqin is typical temperature desert zone, with an average annual precipitation of $115.9 \mathrm{~mm}$, evaporation of $2452.7 \mathrm{~mm}$ and air humidity of $49 \%$. Average annual temperature of $7.7^{\circ} \mathrm{C}$, the extremely highest temperature of $41.0^{\circ} \mathrm{C}$ and the lowest one of $-30.8^{\circ} \mathrm{C}$. Average wind velocity of $2.4 \mathrm{~m} \cdot \mathrm{s}^{-1}$, the highest wind velocity of $25.0 \mathrm{~m} \cdot \mathrm{s}^{-1}$, threshold velocity of $4.5-5.0 \mathrm{~m} \cdot \mathrm{s}^{-1}$. The vegetation in Minqin has small diverse plant communities and typical desert drought-resistant species, such as, Nitraria tangutorica, Reamuria soongorica, Tamarix ramosissima, Calligonum mongolicum, Haloxylon ammodendron, Artemisia arenaria DC, Potaninia mongolica, Salsola passerine, Kalidium foliatum, Apocynum venetum, Agriophyllum arenarium, Corispermum patellifome, Glycyrrhiza uralensis and so on.

Natural and artificial plants in Minqin region are degraded rapidly in recent decades because groundwater table declined by well pumping for farming, and vegetation coverage is about $1 \%-20 \%$.

\section{B. Experimental Materials and Methods}

Aeolian Dust Samplers (ADS) employed to gather aeolian dust, it includes a dust sampler and a wind vane which revolves round an axis (Fig. 2). The top and bottom of the dust collecting box in the sampler covered by fine nets of $0.12 \mathrm{~mm}$ and $1.0 \mathrm{~mm}$ for dust collecting, a side open of $20 \mathrm{~mm} \times 50 \mathrm{~mm}$ is opposite to the arc side for horizontal dust collection. When dust sampler is put in the framework of wind vane, ADS (China Patent: ZL 032 62576.6) starts work, and dust is gathered into the dust sampler automatically with wind directions and velocity changes.

A $50 \mathrm{~m}$ high steel tower above the ground was set up in Minqin natural desert area, 15 ADS (No.01 - No.15) were fixed with the tower windward side at the height of 0.50 , $1.0,3.0,5.0,9.0,13.0,17.0,21.0,25.0,29.0,33.0,37.0$, 41.0, 45.0, 49.0m and worked all time. Dust masses were collected into weighed sample bag respectively after each sand-dust storm event and end of the month from 29, Apr., 2007 to 29, May, 2008. each sample was put into thermostat drier of $80^{\circ} \mathrm{C}$ for 12 hours (DHG-9055A), then, weighed using a $1 / 10000 \mathrm{~g}$ electronic balance (MD 100-2) and dust mass data was recorded. Meanwhile, wind velocities derived every 5 minutes at the height of $9.0 \mathrm{~m}$ on the tower windward side by standard automatical anemoscope, and the granularity of dust masses was measured by MASTERSIZER (Malvern).

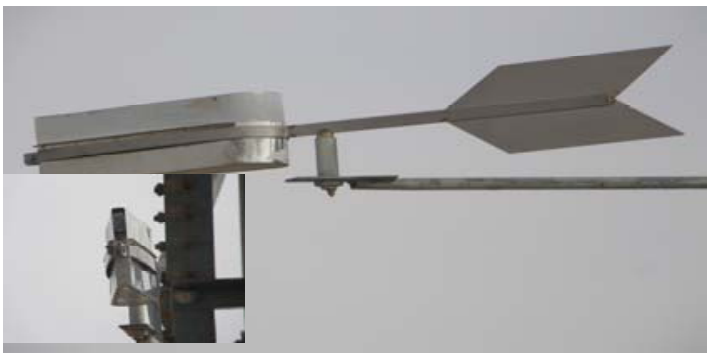

Fig. 2. Experimental arrangement of ADS 


\section{RESULTS AND DISCUSSION}

\section{A. Vertical Distribution on Dust Mass}

The different month had one or more times dust collection according to sand-dust storm activities. The total dust mass data at the same ADS height layer was added together monthly, and its vertical distribution within $50 \mathrm{~m}$ above the ground in Minqin natural desert region was presented from May, 2007 to May, 2008( Fig. 3), it showed that the dust particle concentration decays exponentially with the height by $q_{\mathrm{h}}=a+b \exp (-h / c)(1)$.

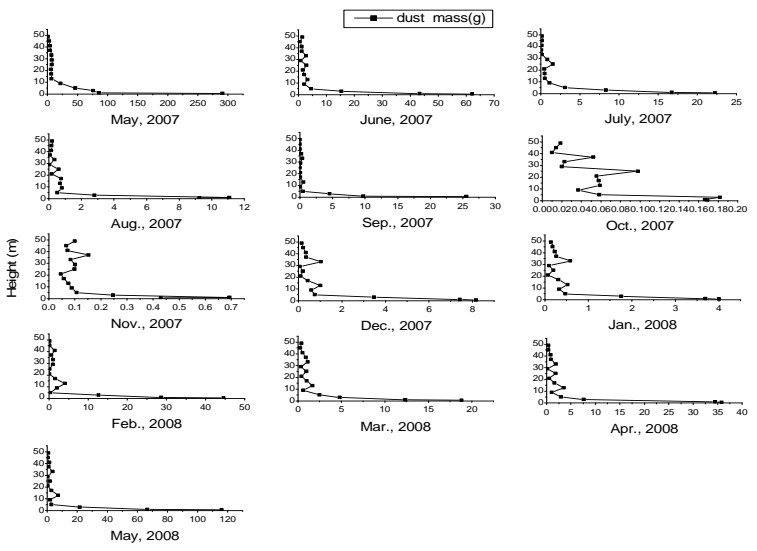

Fig. 3 The monthly dust mass (g) at different ADS height layer (m) in the tower from May, 2007 to May, 2008.

where, $q_{h}$ is the dust mass at height $(h)$ in grams per meter per month, $h$ is height in meters, $a, b$ and $c$ are regressive coefficients. Table 1 indicated that the correlation between dust mass and height was reasonably well. On the monitoring observation for a year round, the correlation coefficient $\mathrm{R}^{2}$ was over 0.95 in 10 months and was less than 0.93 in 3 months of Aug., Oct., and Nov., 2007, a seldom strong air current happened and formed some sand-dust in Sep., 2007, so, it was except, implying that $\mathrm{R}^{2}$ was rather well expression in strong wind and drought season, and good expression in weak wind and raining season in a year round. ADS height was nearer to the ground, the dust mass was more and its difference between neighboring ADS was obvious with height, too. However, dust mass was reduced remarkably with the height increasing and its difference between neighboring ADS was also reduced with height (Fig. 3). Dust mass of 23 groups at 15 ADS height layers was collected from May, 2007 to April, 2008, the average percentage of dust mass at each ADS height layer from $0.5 \mathrm{~m}$ to $49.0 \mathrm{~m}$ to total ones of $1123.146 \mathrm{~g}$ in the year was $46.49 \%, 22.66 \%, 12.25 \%, 5.54 \%, 2.71 \%, 2.01 \%, 1.32 \%$, $0.83 \%, 1.42 \%, 0.97 \%, 1.43 \%, 0.78 \%, 0.82 \%, 0.43 \%$ and $0.35 \%$ respectively. Its $5 \mathrm{ADS}$ height layers near to the ground was about $89.65 \%$ of total dust mass, others was $10.35 \%$, it showed that dust mass at the 5 ADS height layers from $0.5 \mathrm{~m}$ to $9.0 \mathrm{~m}$ above the ground was reduced rapidly around 2 times between neighboring ADS with the height increasing, other ADS height layers were not as obvious as than that of the 5 ADS. So, for general sand-dust storm, the sand-dust mass in arid desert areas was mainly concentrated in $0-5.0 \mathrm{~m}$ or even $0-9.0 \mathrm{~m}$ vertical section above the ground according to the wind and sand-dust conditions. Dust mass was just a little and reduced slowly above the heights and some ADS height layers even increased more a little than lower ones because of unstable dust plume, tornado, small dust devils and other wind-dust conditions in different height. It also revealed that the dust mass concentration in ADS was varied with the wind velocity, Fig. 3 and Table 1 showed vertical distribution of dust mass was influenced clearly by wind velocity.

TABLE 1. CORRELATION BETWEEN DUST MASS $Q_{H}$ AND HEIGHT $H$ MONTHLY

\begin{tabular}{|c|c|c|c|c|c|c|c|}
\hline \multirow[t]{2}{*}{ No. } & \multirow[t]{2}{*}{$\begin{array}{l}\text { Period } \\
\text { (month) }\end{array}$} & \multicolumn{2}{|c|}{$\begin{array}{l}\text { Wind velocity } \\
\left(\mathrm{ms}^{-1}\right)\end{array}$} & \multirow[t]{2}{*}{$a$} & \multirow[t]{2}{*}{$b$} & \multirow[t]{2}{*}{$c$} & \multirow[t]{2}{*}{$\mathrm{r}^{2}$} \\
\hline & & $V_{\text {Max. }}$ & $\mathrm{V}_{\text {Ave. }}$ & & & & \\
\hline 01 & May & 22.9 & 4.14 & 15.0326 & 1690.20 & 0.3163 & 0.95 \\
\hline 02 & June & 19.8 & 3.38 & 1.7639 & 81.7620 & 1.5704 & 0.99 \\
\hline 03 & July & 16.8 & 3.05 & 0.4369 & 26.4651 & 2.3139 & 0.99 \\
\hline 04 & Aug. & 15.7 & 2.99 & 0.2718 & 13.4569 & 2.0965 & 0.93 \\
\hline 05 & Sep. & 18.1 & 2.89 & 0.4594 & 64.2244 & 0.5293 & 0.97 \\
\hline 06 & Oct. & 14.3 & 2.22 & 0.0327 & 0.1611 & 5.6930 & 0.74 \\
\hline 07 & Nov. & 13.6 & 2.28 & 0.0804 & 0.5982 & 2.6429 & 0.83 \\
\hline 08 & Dec. & 18.5 & 1.72 & 0.3527 & 10.1515 & 2.3272 & 0.98 \\
\hline 09 & Jan. & 5.9 & 2.02 & 0.2368 & 4.9054 & 2.3570 & 0.98 \\
\hline 10 & Feb. & - & - & 1.0094 & 58.3177 & 1.5338 & 0.98 \\
\hline 11 & Mar. & 18.7 & 3.73 & 0.8036 & 23.8315 & 1.5804 & 0.99 \\
\hline 12 & Apr. & 19.7 & 3.17 & 1.0274 & 50.2963 & 1.7570 & 0.97 \\
\hline 13 & May & 21.5 & 3.38 & 2.3189 & 174.009 & 1.1052 & 0.98 \\
\hline
\end{tabular}

\section{B. Vertical Dust Production Capacity Monthly}

In the experiment, dust mass data of vertical section at 15 ADS height layers at the tower was added together every month respectively, and it was presented monthly from May, 2007 to May, 2008(Fig. 4(a)). It showed that the main dust period is from February to May, the maximum is in May, it was coincided with the windy and lowest vegetation season in Spring, then, it was declined month by month, the low dust period is August to November in Autumn, it was coincided with the weak wind and best vegetation season, the minimum is in Oct., and then, it was increased in Winter and Spring from December to next May. Meanwhile, the monthly dust mass at $5.0 \mathrm{~m}$ above the ground at the same tower was also presented from May, 2007 to May, 2008 (Fig. 4(b)). It revealed that the general dust mass increasing and decreasing in Fig. 4(a) was similar to Fig. 4(b) monthly, but its difference was several times between 15 ADS dust mass total within $50 \mathrm{~m}$ above the ground and just ones at $5.0 \mathrm{~m}$ high, and their monthly dust mass proportion also has some differences, which showed that different height position above the ground has some specific dust mass concentration in quality and quantity at the same time. 


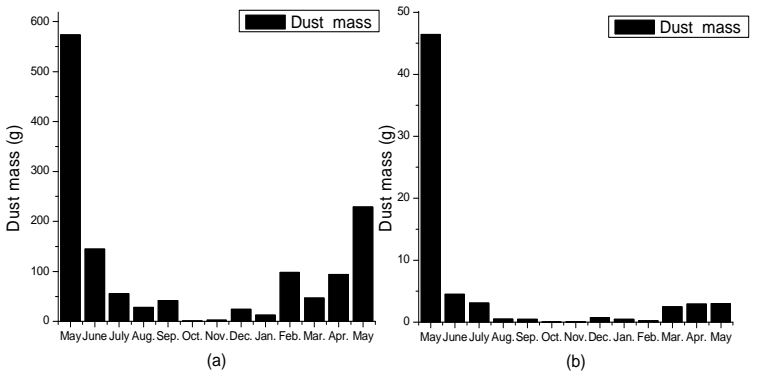

Fig.4. The monthly dust mass collected from May, 2007 to May, 2008 (a) Total dust mass at $15 \mathrm{ADS}$ height layers (b) Dust mass at $5.0 \mathrm{~m}$ high

\section{Vertical Distribution on Dust Grain Size}

Dust mass data was employed after each sand-dust storm event and end of the month in a year round in the experiment. Totally 120 samples of 8 groups were selected and ADS No. represents 15 ADS heights from $0.5 \mathrm{~m}-49.0 \mathrm{~m}$ above the ground, $d_{\max }$ is the particle size maximum, $\mathrm{M}_{\mathrm{Z}}$ is mean size diameter ( $\Phi$ value and millimeter), $\sigma_{\mathrm{I}}$ is graphic standard deviation or phi sorting, $\mathrm{Sk}_{\mathrm{I}}$ is graphic skewness or phi skewness, $\mathrm{K}_{\mathrm{G}}$ is graphic kurtosis or phi kurtoiss.

Grain-size was analyzed. Particle size was from sands to fine silts in each ADS layer, size scales standard came from Udden (1914) and Wentworth (1922) modifications proposed by Friedman \& Sanders (1978), the biggest particle size was $0.8 \mathrm{~mm}$, which just occurred three times at ADS of $0.5 \mathrm{~m}$ high above the ground and wind velocity was more than $20 \mathrm{~ms}^{-1}$ in the monitoring year. Group samples showed that the maximum and mean dust particle size was reduced with the height increasing (table 2), varied with wind velocities, and also revealed the same situation with the cumulative percentage size-frequency at $15 \mathrm{ADS} 5.0 \mathrm{~m}$, even $9.0 \mathrm{~m}$ was reduced continually in accordance with wind velocity, however, it was varied a little at its neighboring ADS layers from $9.0 \mathrm{~m}-49.0 \mathrm{~m}$ above the ground (Table 2). According to the graphical statistics, the more nearer to the ground, the more cumulative percentage of coarse size-frequency was presented (Fig. 5). Mean particle size at the ADS height of $0.5 \mathrm{~m}, 1.0 \mathrm{~m}, 3.0 \mathrm{~m}$, even $9.0 \mathrm{~m}$ was reduced continually with wind velocity. Parameter value modified by Folk \&Ward 1957, Standard deviation $\left(\sigma_{I}\right)$ of dust size vertical distribution at the samples of No.01-No.04 was poorly sorted, No.05-No.15 was very poorly sorted and revealed that $\sigma_{\mathrm{I}}$ had a increasing was very positively fine skewed; phi kurtosis $\left(\mathrm{K}_{\mathrm{G}}\right)$ at samples No.01-No.04 and No.13 was very leptokurtic, No.05-No.15 except No.13 was leptokurtic and showed
TABLE 2. GRAIN-SIZE PARAMETER OF SAND-DUST COLLECTED AT 15 ADS HEIGHTS AT THE TOWER IN JULY, 2007.

\begin{tabular}{lllllll}
\hline $\begin{array}{l}\text { ADS } \\
\text { No. }\end{array}$ & $\mathrm{d}_{\max } / \mathrm{mm}$ & $\mathrm{Mz} / \Phi$ & $\mathrm{Mz} / \mathrm{mm}$ & $\sigma_{\mathrm{I}}$ & $\mathrm{Sk}_{\mathrm{I}}$ & $\mathrm{K}_{\mathrm{G}}$ \\
\hline 01 & 0.5 & 3.400 & 0.095 & 1.234 & 0.315 & 2.229 \\
02 & 0.25 & 3.619 & 0.081 & 1.286 & 0.435 & 2.402 \\
03 & 0.25 & 3.698 & 0.077 & 1.045 & 0.343 & 1.768 \\
04 & 0.25 & 4.624 & 0.041 & 1.993 & 0.589 & 1.560 \\
05 & 0.25 & 4.871 & 0.034 & 2.211 & 0.625 & 1.385 \\
06 & 0.25 & 4.789 & 0.036 & 2.078 & 0.585 & 1.273 \\
07 & 0.25 & 4.712 & 0.038 & 2.020 & 0.553 & 1.343 \\
08 & 0.2 & 5.100 & 0.029 & 2.345 & 0.516 & 1.414 \\
09 & 0.25 & 4.928 & 0.033 & 2.074 & 0.520 & 1.207 \\
10 & 0.18 & 5.373 & 0.024 & 2.259 & 0.449 & 1.098 \\
11 & 0.2 & 4.906 & 0.033 & 2.047 & 0.513 & 1.295 \\
12 & 0.2 & 5.832 & 0.018 & 2.520 & 0.339 & 1.003 \\
13 & 0.2 & 4.965 & 0.032 & 2.259 & 0.523 & 1.522 \\
14 & 0.2 & 4.780 & 0.036 & 2.134 & 0.631 & 1.444 \\
15 & 0.18 & 5.637 & 0.020 & 2.248 & 0.465 & 1.325 \\
\hline
\end{tabular}

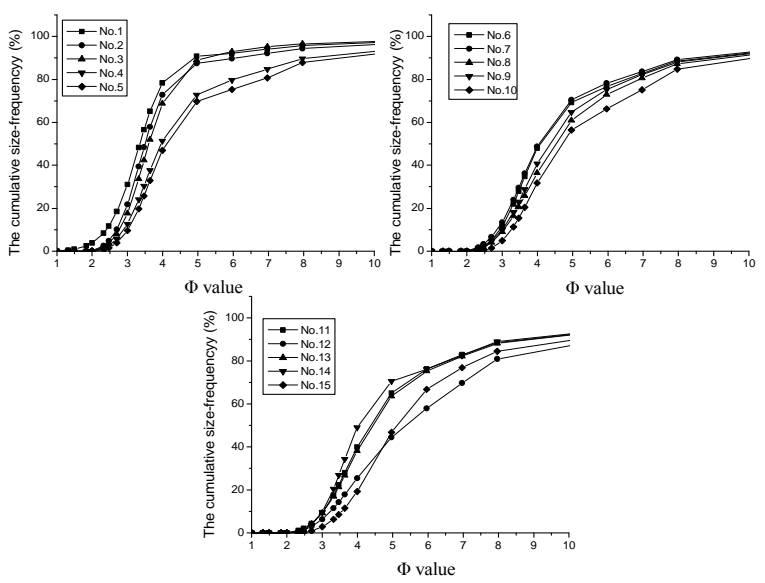

Fig 5. The cumulative percentage size-frequency curves at 15 ADS heights from $0.5 \mathrm{~m}-49 \mathrm{~m}$ in July, 2007.

\section{The Relationship between Wind Condition and Dust Vertical Distribution}

The dust mass was collected at every ADS at the same time after each sand-dust storm event from 29, Apr., 2007 to 29, June, 2007, Its vertical distribution under different wind conditions was presented in Minqin natural desert region (Fig. 6), it showed that the dust particle concentration decays exponentially with the height by Eq. (1). It indicated that the correlation between dust mass concentration and height in vertical section was good and the correlation coefficient $\mathrm{R}^{2}$ was over 0.91 . $\mathrm{q}_{\mathrm{h}}$ was decided by two parts of $\mathrm{a}$ and $\operatorname{bexp}(-\mathrm{h} / \mathrm{c})$, and coefficient $\mathrm{a}, \mathrm{b}$, and $\mathrm{c}$ were mainly driven by wind condition, it revealed that dust concentration increases with wind velocity at each sand-dust storm event .

On the monthly and timely observation for a year round, Coefficient $a$ in equation (1) was a constant, $a$ value was mainly driven by wind velocity, and increased with wind velocity, the dust concentration varied in accordance with $a$ value. Coefficient $b$ increased with wind velocity, too, it 
was much more obvious and sensitive than $a$ value with wind velocity, $a$ and $b$ was a positive correlation, implying that the dust particle concentration decays more rapidly as wind velocity decreases. However, coefficient $c$ in the equation decreased with wind velocity increasing and increased with wind velocity decreasing well (Table 1). Fig. 7 revealed that sand-dust storms were the most frequent in April and May in Minqin desert region, and dust mass was the biggest, so, coefficient $a$ and $b$ value was the most, they were reduced with the wind velocity decreasing from June to November month by month, especially, a seldom gale happened in September, the $a$ and $b$ were just raised with the wind, and then, with wind season coming in Winter and in Spring next year, the $a$ and $b$ was followed the wind condition. However, the coefficient $c$ was just negative to $a$ and $b$ well (Fig. 7).

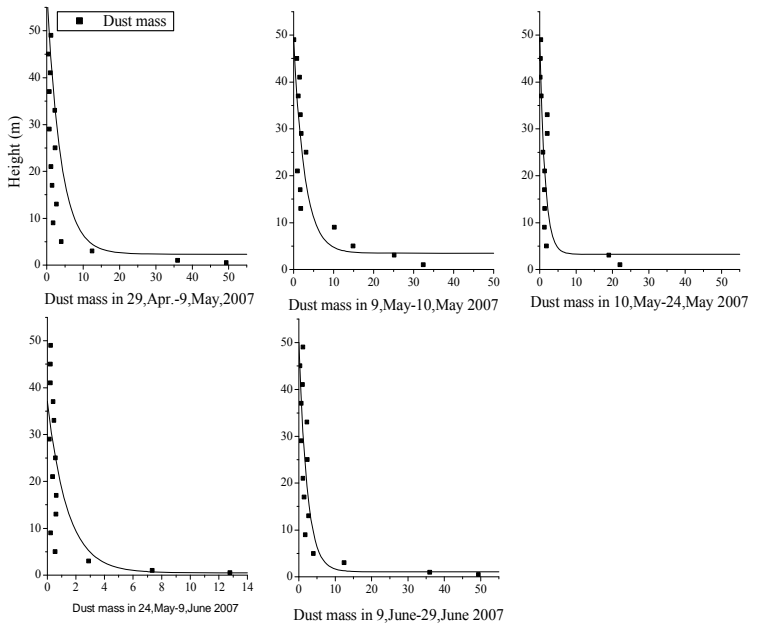

Fig. 6. Timely dust mass vertical distribution and its correlation between dust mass and height from 29, Apr. to 29, June, 2007

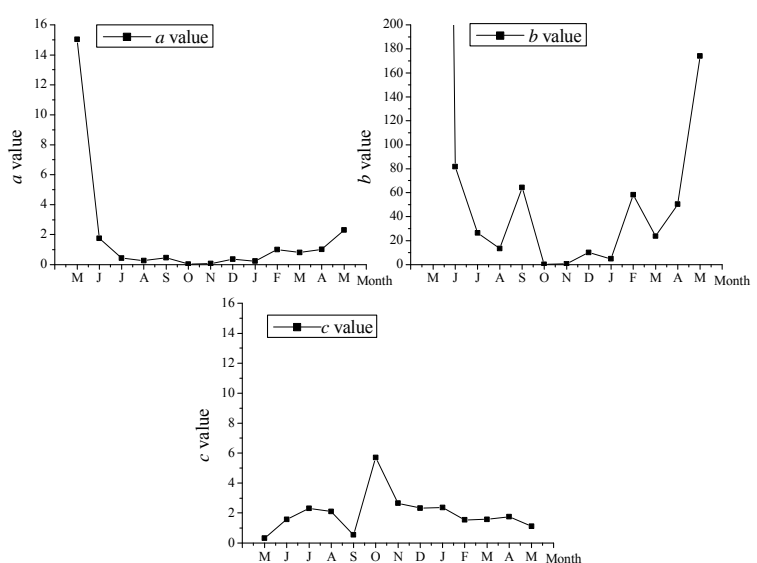

Fig. 7 The monthly $a, b, c$ value in the tower from May, 2007 to May, 2008

\section{E. Discussion}

The function (Eq (1)), which has been got for the sand-dust vertical distribution profile above the ground in Minqin natural desert area, showed that the dust particle concentration decays exponentially with the height. Most published results suggest that the blown sand transport rate in saltation decays exponentially with height ( Takeuchi, 1980; Zhibao Dong et al., 2002; Xiaoping Liu, Zhibao Dong, 2004). Whereas, Takeuchi (1980) thought that suspension profiles fell off by a power function with height, Anderson and Hallet (1986) suggested an exponential for the saltation flux profile and a power function for the suspension profile. However, the field monitoring observation which combined saltation with suspension in the sand-dust source area from $0.0 \mathrm{~m}-49.0 \mathrm{~m}$ above the ground concluded that vertical distribution of sand-dust mass was agreed the function Eq (1), and found to agree rather well monthly in windy season and good in weak windy season in a year round (table 1).

On the observation, the dust mass was reduced rapidly with the height increasing, was reduced continually under $5.0 \mathrm{~m}$ high above the ground or even $9.0 \mathrm{~m}$ high when wind velocity was big enough. However, its difference between neighboring ADS layers above $5.0 \mathrm{~m}$ or even $9.0 \mathrm{~m}$ high was reduced, and dust mass of some specific ADS height layers was even more a little than that of lower neighboring ones. It was the saltation and suspension mixed layer near to the ground when sand-dust storm happened, the more nearer to the ground, the more saltation and suspension particles could be concentrated at the ADS near to the ground, the saltation particles was reduced rapidly with the height increasing, so the dust mass was reduced obviously. Wind velocity and disorderly air current were increasing with the height, suspension particles are very light, It could be driven by a breeze, sometimes, parts of unstable dust plumes, tornadoes, small dust devils and other dust activities touched some ADS height layers at the tower, so, the dust mass concentration was influenced irregularly.

The particle size reduced and finer particles increased with the height increasing. The saltation and suspension particles were mixed together above the ground to a certain height though their proportions were different and varied with the height. The more nearer to the ground, the more saltation and suspension particles at vertical section were from local land, the more higher to the ground, the more Fig. fine dust particles were from longer distance because most saltation particles could not move a long distance and local suspension ones nearby monitoring site could not entrain to high sky directly under the wind power. When saltation and suspension particles at local surroundings almost disappeared or disappeared, fine suspension particles which came from distant area concentrated at higher ADS layers and suspended in a certain space scale, the particles are also finer and finer with height increasing.

\section{CONCLUSION}

A $50 \mathrm{~m}$ high steel tower was set up in Minqin sand-dust source area, 15 ADS were fixed to the tower from $0.50 \mathrm{~m}-$ 
$49.0 \mathrm{~m}$ above the ground, dust mass was collected and treated respectively after each sand-dust storm event and end of the month in a year round. The vertical distribution of dust mass monthly and timely agreed the function $(\mathrm{Eq}$ (1)), it showed that the dust particle concentration decays exponentially with the height. The correlation between dust mass and height was reasonably well.

$a, b$ and $c$ were Coefficients in equation (1), mainly driven by wind velocity, $a$ and $b$ increased with wind velocity, $b$ was more obvious and sensitive than $a$, implying that the dust particle concentration decays more rapidly as wind velocity decreases. However, $c$ in the equation decreased with wind velocity increasing and increased with wind velocity decreasing well.

The maximum and mean dust particle size was reduced with the height increasing and varied with wind velocity. Standard deviation $\left(\sigma_{\mathrm{I}}\right)$ of dust size vertical distribution had a increasing tendency with the height from poorly sorted to very poorly sorted; all phi skewness $\left(\mathrm{Sk}_{\mathrm{I}}\right)$ was very positively fine skewed; phi kurtosis $\left(\mathrm{K}_{\mathrm{G}}\right)$ had a reduced tendency with the height increasing from very leptokurtic to leptokurtic. It all revealed that dust particles from local and remote areas extensively, Minqin region is not only a main dust source area but also a main corridor of sand-dust storm in north-western China.

\section{ACKNOWLEDGMENT}

We gratefully acknowledge the funding received from the Natural Science Foundation of China (31460219) and Gansu provincial project (144WCGA171).

\section{REFERENCES}

[1] Amal Kar, Kazuhiko Takeuchi. 2004. Yellow dust: an overview of research and felt needs. Journal of Arid Environments. 59, 167-187.

[2] Anderson, R.S., Hallet, B., 1986. Sediment transport by wind: toward a general model. Geological Society of America Bulletin, 97, 523-535.

[3] Breuning-Madsen H, Awadzi TW. 2005. Harmattan dust deposition and particle size in Ghana. Catena 63: 23-38.

[4] Chang,Z., Zhao, M. 2006. Study on desert ecology in Minqin. Gansu Scientific and Technological Press, Lanzhou, pp.30-37.

[5] D'Almeida, G. A., Jaenicke, R., Roggendorf, P. and Richter, D. 1983. New sunphotometer for network operation. Applied Optics, 22, 3796-3801.

[6] Dong, Z., Liu, X., Wang, H., Zhao, A., Wang, X. 2002. The flux profile of blowing sand cloud: a wind tunnel investigation. Geomorphology, 49, 219-230.

[7] Dong, Z., Wang, H., Zhang, X., Michael Ayrault. 2003. Height profile of particle concentration in an aeolian saltating cloud: A wind tunnel investigation by PIV MSD. Geophysical Research Letters, 30, SDE $12-1-12-4$.

[8] Dong, Z., Wang, H., Liu, X., Wang, X. 2004. The blown sand flux over a sandy surface: a wind tunnel investigation on the fetch effect. Geomorphology, 57, 117-127.

[9] Drees, L. R., Manu, A. and Wilding, L. P. 1993. Characteristics of aeolian dusts in Niger, West Africa, Geoderma, 59, 213-233.

[10] Du, M., Yonemura, S., Maki,T., Yamata, Y., Shen, Z., Shen, Y., Wang, W., Kawashima, S., Inoue, S., 2002. Characteristics of dust emission at farmland in Dunhuang, China. Earth Environment 7 (2), 187-195 (in Japanese).

[11] Fryrear, D. W. 1986. A field dust sampler, Journal of Soil and Water Conservation, $41,117-120$
[12] Fryrear, D.W., Stout, J.E., Hagen, L.J., Vories, E.D., 1991. Wind erosion: field measurement and analysis. Transactions of the ASAE 34, 155- 160 .

[13] Du, M., Yonemura, S., Maki,T., Yamata, Y., Shen, Z., Shen, Y., Wang, W., Kawashima, S., Inoue, S., 2002. Characteristics of dust emission at farmland in Dunhuang, China. Earth Environment 7 (2), 187-195 (in Japanese).

[14] Fryrear, D.W., Saleh, A., 1993. Field wind erosion: vertical distribution. Soil Science 155, 294-300.

[15] Gillette DA, hanson KJ.1989. Spatial and temporal variability of dust production caused by wind erosion in the United States. J Geophys Res. 94/D2:2197-2206.

[16] Goodman, G. T., Inskip, M. J., Smith, S., Parry, G. D. R. and Burton, M. A. S. 1979. The use of moss-bags in aerosol monitoring, in Morales (1979) 71-79.

[17] Goosens, D. 1985.The granulometric characteristics of a slowly moving dust cloud. Earth Surface Processes and Landforms, 10, 353-362.

[18] Hall DJ, Upton SJ, Marsland GW. 1994. designs for a deposition gauge and a flux gauge for monitoring ambient dust. Atmos Environ. 28, 2963-2979.

[19] HolbenB., Eck TF, Fraser RS. 1991. Temporal and spatial variability of aerosol optical depth in the Sahel region in relation to vegetation remote sensing. Int J Remote Sensing. 12, 1147-1163.

[20] Iino N., Kinoshita K., Tupper AC, Yano T. 2004. Detection of Asian dust aerosols using meteorological satellite data and suspended particulate matter concentrations. Atmos Environ. 38, 6999-7008.

[21] Legrand M., Bertrand JJ, Desbois M., Meneger L., Fouquart Y. 1989. The potential of infrared satellite data for the retrieval of Saharan dust optocal depth over Africa. J Appl Meteorol. 28, 309-318.

[22] McTainsh, G. H. 1980. Harmattan dust deposition in northern Nigeria. Nature. 286, 587-588.

[23] McTainsh, G. H., Leys J, Nickling WG. 1999. Wind erodibility of arid lands in the Channel Country of Western Queensland, Australia. Z Geomorphol Suppl 116: 113-130.

[24] Middleton, N. J., Goudie, A. S. and Wells, G. L. 1986. The frequency and source areas of dust storms, in Nickling (1986) 237-260.

[25] Middleton, N. J. 1986. Dust storms in the Middle East. Journal of Arid Environments. 10, 83-96.

[26] Nickling, W. G. and Gillies, J. A. 1993. Dust emissions and transport in Mali, West africa. Sedimentology. 40, 859-863.

[27] Offer, Z. I. And Goosens, D. 1990. Airborne dust in the northern Negev Desert (January -December 1987) general occurrence and dust content measurement. Journal of Arid Environments. 18, 1-20.

[28] Pisani G., Spinelli N., D’Avano L., Boselli A., Wang, X., Papayannis A. 2005. Atmospheric African mineral dust monitoring with Raman Lidar over Napoli. Geophys Res Abstr. 7, 09752.

[29] Qian, G., Dong, Z. 2004. Discussions on different dust trapping methods and on some related topics. Journal of Desert Research. 24, 779-782.

[30] Reid JS, et al. 2003. Analysis of measurements of Saharan dust by airborne and ground-based remote sensing methods during the Puerto Rico dust experiment (PRIDE). J Geophys Res. 108 (D19), doi:10.1029/2002JD0022493.

[31] Tegen I., Fung I. 1994. Modelling of mineral dust in the atmosphere: sources tranport and optical thickness. J Geophys Res. 99(D11): 22879-22914.

[32] Wang, X., Dong, Z., Yan, P., Yang, Z., Hu, Z., 2005b. Surface sample collection and dust source analysis in northwestern China. Catena 59, 35-53.

[33] Wang, X., Dong, Z., Zhang, J., Liu, L., 2004b. Modern dust storms in China: an overview. Journal of Arid Environments 58, 559-574.

[34] Yang, G., Xiao, H., Tuo, W., 2001. A case study on the sand dust storm of north-western China. In: Lu, Q (Ed.), On Sand Dust Storms Worldwide. Meteorologic Press, Beijing, pp. 157-184. 
[35] Zhang, X., Arimoto, R., An, Z., 1997. Dust emission from Chinese desert sources linked to variations in atmospheric circulation. Journal of Geophysical Research 102 (23D), 28041-28047.
[36] Zhang, X., Arimoto, R., Zhu, G., Chen T., Zhang, G., 1998. Concentration, size-distribution and deposition of mineral aerosol over Chinese desert region. Tellus 50B: 317-330. 